\title{
Hemoglobinuria posparto en vacas de tres rebaños lecheros de la región del Bío-Bío, Chile
}

\section{Postpartum haemoglobinuria in dairy cows of the Bio-Bio region, Chile}

\author{
Mirela Noro, ${ }^{1 *}$ Ph.D, Fernando Wittwer M, M.Sc. \\ ${ }^{1}$ Universidad Austral de Chile, Instituto Ciencias Clínicas Veterinarias. Valdivia, Chile. *Correspondencia: \\ mirelanoro@gmail.com.
}

Recibido: Febrero de 2011; Aceptado: Agosto de 2011.

\section{RESUMEN}

La hemoglobinuria posparto es una enfermedad metabólica esporádica que presentan las vacas lecheras, manifestándose dentro de las 6 semanas posparto asociada al rápido incremento de la producción de leche al inicio de la lactancia. Se caracteriza por una anemia aguda regenerativa por hemólisis intravascular con hemoglobinuria. Entre los factores que predisponen a su presentación están la ingesta de una dieta carente en fósforo, cobre o selenio, o bien concomitante a la presencia de agentes hemolíticos en plantas crucíferas como el nabo o colza. El trabajo describe aspectos relacionados a la presentación de brotes de la enfermedad en tres rebaños lecheros de la región del Bío-bío, Chile, con hipofosfatemia asociada a la incorporación de derivados de la remolacha azucarera en la dieta.

Palabras clave: Hemoglobinuria, hipofosfatemia, parto, vacas lecheras (Fuentes: CAB, AIMS).

\section{ABSTRACT}

Bovine postpartum hemoglobinuria is a metabolic disorder observed sporadically in dairy cows up to 6 weeks postpartum associated to increasing milk production. It is characterized by an acute intravascular hemolytic anemia with hemoglobinuria. It presentation has been associated to diets with low content of phosphorus, cooper or selenium, as well as the ingestion of hemolytic substances present in some plants of the genus Brassica commonly used as forages (turnips, rapeseed). The aim of this work is to describe clinical aspects related to the presentation of this disease in three dairy herds with hypophosphatemia induced by the inclusion of sugar beet by-products in the diet.

Key words: Dairy cows, hemoglobinuria, hyphophosfatemia, parturient (Sources: CAB, AIMS). 


\section{INTRODUCCIÓN}

La hemoglobinuria posparto es una enfermedad metabólica asociada a carencia de fósforo, cobre o selenio que se presenta como brotes esporádicos en rebaños lecheros de países con sistemas pastoriles o con uso de suplementos con brassicas (1). Hasta un $50 \%$ de las vacas pueden presentar signos evidentes de la enfermedad $(1,2)$. La tasa de mortalidad es variable, pudiendo alcanzar hasta un $50 \%$ entre los animales afectados (1).

La enfermedad, en su síndrome hemolítico, es observada en vacas entre 7 a 45 días posterior al parto. Se relata una mayor presentación en vacas de elevada producción lechera $(1,3)$ de 2 a 3 años de edad (2). Sin embargo, se presenta en un amplio rango de edad, condición corporal y productividad $(1,4)$; siendo raramente afectadas las razas de carne (1). En la mayoría de los países con climas de marcada estacionalidad invierno - verano, la mayor incidencia de la enfermedad ocurre a final del invierno, asociado a estabulación prolongada y al consumo de alimentos carentes en fósforo $(1,4)$. En el Reino Unido se presenta al inicio del verano, especialmente cuando los animales pastorean en praderas y suelos carentes en fósforo, o en periodos de sequía (1).

Etiopatogenia. Dentro de los factores etiológicos de la hemoglobinuria posparto esta la carencia de fósforo, macroelemento esencial para mantención del metabolismo energético de los eritrocitos. La hipofosfatemia prolongada es considerada la causa más importante de la hemoglobinuria. En Nueva Zelanda se ha asociado la enfermedad con otras entidades como hipocupremia por alta ingesta de molibdeno y posiblemente a la carencia de selenio $(1,5,6)$. La asociación de la enfermedad con la ingesta de plantas crucíferas no ha sido evidenciada con exactitud; ya que en varios casos no hay una relación de la ingesta de esas plantas con la enfermedad (7).

La enfermedad, cuando está asociada con hipofosfatemia, es causada por una carencia de fósforo, correlacionada con las altas demandas de la lactación. En humanos, perros, ovinos (5) y bovinos la hipofosfatemia está asociada con una reducción de la tasa glucolítica que resulta en una baja síntesis del ATP eritrocitario (8) y de glutatión reducido, el cual controla el estrés oxidativo celular; además, se observa un incremento en la concentración de metahemoglobina (3). El ATP es requerido para la mantención de la forma y plasticidad del eritrocito. Cuando las concentraciones de ATP están disminuidas la baja actividad de la bomba Na-K ATPasa incrementa la difusión pasiva de $\mathrm{Na}$ al interior del eritrocito ingresando agua y culminando en una alteración estructural y transformándose en esferocitos, los cuales pierden su capacidad de deformidad $(8,9)$, incrementando la fragilidad de su membrana con su rápida remoción de la circulación, o fragmentación cuando adquieren alta velocidad en las arteriolas, generando una hemólisis intravascular y consecuentemente una anemia aguda regenerativa. La hemoglobina libre produce ictericia y por otro lado rebasa la filtración renal y por consiguiente genera la hemoglobinuria (10).

La enfermedad se ha producido experimentalmente en un animal sometido a una dieta deficitaria en fósforo durante un periodo de tres gestaciones en el cual los signos de carencia de fósforo fueron observados 18 meses previos al desarrollo de la hemoglobinuria, la cual respondió a la suplementación con fósforo (1).

La carencia de cobre es considerada en Nueva Zelanda un factor etiológico en la presentación de la enfermedad, ya que en algunos rebaños afectados se evidencian bajas concentraciones de este elemento en hígado (1.4 a $11.1 \mathrm{mg} / \mathrm{kg}$ MS) y plasma $(0.2$ a $0.7 \mathrm{mg} / \mathrm{L})(1,11)$. Además, la suplementación con cobre disminuye la incidencia de la enfermedad en rebaños que se encuentran en áreas carentes (7). La patogenia de la enfermedad se relaciona con la carencia de cobre por una menor actividad de la enzima superóxido dismutasa, la cual protege los eritrocitos del daño oxidativo, fundamentalmente la lipoperoxidación de su membrana (1). 
Los signos son evidenciados durante el invierno e inicio de primavera, cuando aumenta el contenido de molibdeno en el forraje (11), relacionándose también con la aplicación de molibdeno y carbonato de calcio en el suelo, que disminuyen la disponibilidad de $\mathrm{Cu}$ al animal al disminuir su capacidad de absorción, o el contenido en el forraje respectivamente $(1,6)$. La importancia del cobre y posiblemente del selenio en esta enfermedad es debida al uso en la alimentación de bovinos de forrajes carentes de estos minerales, situación que se asocia a una disminución de la capacidad antioxidante (CuZnSOD y GPx) en el eritrocito, lo que incrementa la fragilidad eritrocitaria $(1,5,12)$, siendo necesario su suplementación para prevenir los efectos del consumo de agentes hemolíticos, acorde con lo indicado por algunos autores, si bien no es clara su relación $(8,10)$.

Una situación que se asocia a la carencia de fósforo es cuando concomitantemente se incluye como componente de la dieta la ingesta de plantas crucíferas las cuales, por su bajo contenido de fósforo, agravan la situación anterior. Además, se señala que estas plantas, contienen sulfoxido de S-metilcisteína que se metaboliza en el rumen a dimetildisulfóxido, el cual posterior a su absorción produce lipoperoxidación de la membrana del eritrocito y desnaturaliza la hemoglobina (10). Efecto que es observado cuando las crucíferas son consumidas en elevadas cantidades por un periodo superior a 3 semanas (13).

Los factores relacionados al parto e inicio de la lactancia, pueden acentuar la presentación de casos clínicos en los rebaños, ya que generan lipomovilización y acidosis metabólica leve (14). Es así como el cambio de alimentación del preparto al posparto sin una previa adaptación, la acidosis metabólica, o la cetosis, pueden producir hipofosfatemia, ya que inducen la salida de fósforo de las células hacia el plasma, incrementando su excreción renal como efecto buffer (10). A su vez, cuando se restaura el equilibrio ácido-base el fósforo retorna a las células, produciendo una severa hipofosfatemia (15).
Signos clínicos. Los signos observados en la hemoglobinuria posparto son los de una anemia aguda y en casos mortales de una anemia anóxica. El primer signo observado es la orina de color rojizo o castaño, seguido por inapetencia con cese de la ingesta de alimento y agua, deshidratación, heces secas y oscuras cubiertas de moco, asociadas a la hipertermia de hasta $40^{\circ} \mathrm{C}$, que culmina en una marcada disminución en la producción de leche, inapetencia, debilidad, palidez de mucosas, taquicardia, disnea y aumento del pulso yugular. A su vez no se ha relatado en la literatura efectos sobre la función ruminal. Posteriormente, 2-3 días, se observa ictericia y en algunos animales se presenta pica que se relaciona con la carencia de fósforo (10).

En casos graves, la muerte como consecuencia de la anemia aguda se puede presentar dentro de las primeras 36 horas de observados los primeros signos clínicos. Si la enfermedad sigue por 3 a 5 días, el animal se debilita rápidamente, presentando un adelgazamiento extremo, adoptando una marcha tambaleante y posteriormente decúbito (16). Se puede generar una insuficiencia renal asociada a deshidratación y nefrosis hemoglobinúrica por formación de acúmulos proteináceos dentro de la luz tubular, obstruyendo el flujo intraluminal, o bien la hemoglobina puede causar un efecto tóxico directo sobre el epitelio tubular $(2,4)$.

En casos menos graves el animal sigue comiendo; la convalecencia se prolonga unas 3 semanas y durante su recuperación presenta pica, característica de las carencias de fósforo en la dieta. Generalmente se acompaña de cetosis derivada del balance energético negativo producido por la disminución en la ingesta de alimentos y los animales raramente alcanzan posteriormente la producción de leche esperada (10).

Hallazgos hematológicos. Al examen hematológico se observa la alteración en la molécula de hemoglobina en animales afectados por hemoglobinuria posparto por un elevado porcentaje de eritrocitos con corpúsculos de Heinz, los cuáles son precipitados de hemoglobina oxidada cuando la tasa oxidativa sobrepasa el potencial 
reductor de los eritrocitos. Además, se observa una respuesta regenerativa medular identificada por la presencia de anisocitosis, macrocitosis con policromasia, reticulocitosis, y eritrocitos nucleados en la sangre periférica $(5,15)$. En el frotis sanguíneo se pueden observar que sobre el $50 \%$ de los eritrocitos circulantes son esferocitos y los corpúsculos de Heinz pueden presentarse entre 1 al $50 \%$ de los eritrocitos (5). Otros hallazgos son incremento de la fragilidad eritrocitaria, y leucococitosis neutrofílica durante el cuadro hemolítico (1)

Hallazgos de necropsia. Los principales hallazgos son la ictericia en mucosas y serosas, deshidratación, orina en la vejiga de color pardo rojiza oscura a negra, ligeramente turbia y sin glóbulos rojos, el hígado presenta algunas veces degeneración lipídica como consecuencia del balance negativo de energía. El examen histológico del riñón evidencia nefrosis hemoglobinúrica y el hígado demuestra necrosis centrolobular, atribuidas a la anemia anóxica $(2,4)$.

Tratamiento y prevención. Cuando el animal está gravemente afectado, se requiere de transfusión de sangre, como mínimo 5 litros para una vaca de $550 \mathrm{~kg}$ de peso (16). Se recomienda instaurar el tratamiento rápidamente ya que el retraso en 12 horas puede conducir a un estado irreversible producto de la gravedad de la anemia. Hay que tener cuidado al seleccionar las donadoras, ya que otras vacas del rebaño pueden estar anémicas y no demostrar signos clínicos de la enfermedad, demostrable por una baja manifiesta del hematocrito (9). También, es recomendable utilizar terapia de fluidos como coadyuvante de la transfusión para reducir el riesgo de nefrosis hemoglobinúrica al mejorar la perfusión renal y disminuir su precipitación en los túbulos. Normalmente se realiza un único tratamiento, siendo necesaria una segunda transfusión cuando a las 48 horas el animal aún presenta debilidad, idealmente con sangre del mismo donante (17).

En la fase aguda, se recomienda la administración de fósforo inorgánico (fosfato ácido de sodio al 20\%), 300 ml vía endovenosa y dosis análogas en tres ocasiones por vía subcutánea con intervalos de 12 horas y en dosis similares por vía oral (16). La mayoría de las soluciones que contienen calcio, magnesio y fósforo, contienen sales de fósforo. Un tratamiento alternativo es la administración oral de $120 \mathrm{~g}, 2$ veces al día, de una solución de fosfato dicálcico, o una fuente adecuada de fósforo diariamente durante 5 días, la cual debe ser incluida en la ración (16). Durante la convalecencia se recomienda el uso de hierro y en casos que cursen con cetosis secundaria se requiere un tratamiento anti-cetogénico (16). Como medidas preventivas se recomienda una adecuada ingestión de fósforo, acorde con los requerimientos de mantenimiento $y$ de producción de leche, principalmente al inicio de la lactancia. En zonas deficitarias en cobre o selenio, la suplementación con dichos elementos debería ser indispensable. Cuando se sospecha de una carencia de cobre asociada a la patología es recomendable la administración parenteral de $360 \mathrm{mg}$ de glicinato de cobre, 48 horas posparto (1). Una adecuada suplementación con concentrado también podría aportar un mayor contenido de los elementos involucrados en la hemoglobinuria posparto.

Diagnóstico diferencial. Existen otras enfermedades que cursan con anemia hemolítica aguda, por lo que deben ser diferenciadas de la hemoglobinuria posparto. Entre ellas, la intoxicación por plomo cursa con manifestaciones nerviosas; la intoxicación por nitritos presenta un curso sobreagudo con muerte por cianosis y responde a la administración de azul de metileno; la babesiosis se presenta con garrapatosis masiva; la leptospirosis por Leptospira pomona normalmente produce hemoglobinuria en terneros; y el eczema facial se produce por micotoxicosis por esporosdemina cursando con ictericia sin hemoglobinuria (15). También, se debe hacer un diagnóstico diferencial con enfermedades que cursan con hematuria como la hematuria enzoótica producida por la ingesta de helechos (Pteridium aquilinum), en donde hay orina de color rojo intenso pero con eritrocitos. 


\section{DESCRIPCIÓN DE LOS CASOS}

A continuación se describen la presentación de brotes de la enfermedad en tres rebaños lecheros ubicados en la zona de Los Ángeles, región del Bío-Bío, centro-sur de Chile $\left(37^{\circ} \mathrm{S}, 7^{\circ} \mathrm{O}\right)$.

Lechería 1. El brote, ocurrió a fines de invierno (agosto) en una lechería con 120 vacas Holstein Frisian en ordeño, con una dieta basada en pastoreo de avena y suplementación con subproductos de la remolacha y oleaginosas (raps o colza) (Tabla 1). Una vaca de 6 años y con 20 días posparto fue encontrada muerta a las dos horas posterior a ingresar a la pradera de avena, sin presentar signos de enfermedad durante el ordeño previo al pastoreo. En la necropsia, realizada aproximadamente a las 10 horas post mortem, se observó que la sangre estaba parcialmente coagulada, con un color rojo oscuro "achocolatado", las serosas ictéricas, el hígado de color amarillento oscuro, sin infiltración lipídica visible.

Se emitió un diagnóstico presuntivo de intoxicación por nitritos por el consumo de avena. Al examinar otras vacas, de similar período de lactancia del rebaño, se observó cuatro animales, aislados y decaídos, con leve ictericia conjuntival e inicio de afecciones digestivas manifestadas por dolor poco marcado y en otras se observó signos de pica propios de la carencia de fósforo. A las cuatro vacas enfermas,

Tabla 1. Dieta base ( $\mathrm{kg}$ materia fresca) en las tres lecherías estudiadas, 1,2 y 3 y en dos controles, C1 y C2.

\begin{tabular}{lccccc}
\hline \multirow{1}{*}{ Ingrediente } & $\mathbf{5}$ & $\mathbf{2}$ & $\mathbf{3}$ & $\mathbf{C 1}$ & $\mathbf{C 2}$ \\
\hline Pastoreo avena & 30 & - & - & 30 & - \\
Pastoreo alfalfa & - & 15 & 20 & - & 30 \\
Coseta fresca & 20 & 30 & 20 & 10 & - \\
Hoja remolacha & 15 & - & 15 & - & 15 \\
Ensilaje maíz & - & 10 & - & - & - \\
Heno alfalfa & 4 & 2 & 2 & 20 & 20 \\
Melaza & - & 1 & - & - & - \\
Afrecho de raps & 1 & 1 & 1 & 1 & 1 \\
Concentrado & 5 & 4 & 4 & 5 & 4 \\
Mezcla mineral & 0.15 & - & - & 0.1 & 0.15 \\
\hline
\end{tabular}

se administró una terapia con azul de metileno al $2 \%$ en solución acuosa IV, suero glucosado al $5 \%$ y coleréticos. Dos de las cuatro vacas enfermas murieron dentro de 48 - 72 horas de iniciados los signos clínicos, mientras las otras se recuperaron lentamente siendo posteriormente engordadas y enviadas a feria. A la necropsia se observó lesiones similares a las encontradas en la necropsia del primer animal.

Lechería 2. A fines de invierno en una lechería con 90 vacas Holstein Frisian en lactancia, con una dieta basada en pastoreo y suplementación con subproductos de remolacha y colza (Tabla 1 ), se observó una vaca enferma de un lote con menos de 3 semanas posparto. La vaca presentaba debilidad extrema, mucosas anémicas, la sangre extraida era oscura, diluida y con un tiempo de coagulación superior a los 15 minutos, además de afecciones digestivas. Se administró una terapia similar a la realizada en el caso anterior. La vaca murió a las 36 horas de iniciado los signos clínicos, apreciándose a la necropsia ictericia generalizada, sangre oscura parcialmente coagulada, vejiga con orina rojo oscura y el hígado de color amarillo oscuro sin infiltración lipídica. No se presentaron otros casos en el rebaño.

Lechería 3. A fines de otoño en una lechería con 90 vacas Overo Negro/Holstein Frisian, con dieta en base a pastoreo de alfalfa y subproductos de la remolacha y colza (Tabla 1), se encontró una vaca muerta a las 4 semanas posparto, sin signos clínicos previos. A la necropsia se observó ictericia generalizada con características similares a las vacas afectadas en las dos lecherías anteriores. El veterinario clínico consideró como causa poco probable una enfermedad hemolítica bacteriana, ya que las muestras de hígado fueron negativas a anaeróbicos patógenos.

En un grupo de vacas en lactancia de las tres lecherías problema y de dos lecherías controles en que no se observaron casos clínicos, se realizó un perfil metabólico. En este examen se encontró una marcada hipofosfatemia (Tabla 2) y anemia, estando 
Tabla 2. Concentraciones séricas de fosfato inorgánico (Pi) y de calcio ( $\mathrm{Ca}$ ) en grupos de vacas menos o más de 90 días de lactancia de tres lecherías afectadas por hemoglobinuria pos-parto y valores medios de dos lecherías controles.

\begin{tabular}{|c|c|c|c|c|}
\hline & \multicolumn{2}{|c|}{$\mathrm{Pi}(\mathrm{mmol} / \mathrm{L})$} & \multicolumn{2}{|c|}{$\mathrm{Ca}(\mathrm{mmol} / \mathrm{L})$} \\
\hline & $\begin{array}{l}<90 \\
\text { días }\end{array}$ & $\begin{array}{l}>90 \\
\text { días }\end{array}$ & $\begin{array}{l}<90 \\
\text { días }\end{array}$ & $\begin{array}{l}>90 \\
\text { días }\end{array}$ \\
\hline Lechería 1 & 0.69 & 0.66 & 2.53 & 2.53 \\
\hline Lechería 2 & 0.75 & 0.76 & 2.53 & 2.49 \\
\hline Lechería 3 & 0.80 & 0.87 & 2.49 & 2.64 \\
\hline $\begin{array}{l}\text { Lecherías } \\
\text { controles* }\end{array}$ & 1.38 & 1.44 & 2.24 & 2.27 \\
\hline $\begin{array}{l}\text { Valores de } \\
\text { referencia }\end{array}$ & \multicolumn{2}{|c|}{$1.10-2.30$} & \multicolumn{2}{|c|}{$2.00-2.30$} \\
\hline
\end{tabular}

*Medias de 6 perfiles metabólicos de 21 vacas cada uno de dos lecherías sin casos clínicos.

los otros metabolitos analizados dentro de los rangos de referencia establecidos por el laboratorio (18)(Tabla 3).

Basado en la similitud de la dieta en base a plantas crucíferas, aportada a los animales en las tres propiedades problema (Tabla 1), resultados del perfil metabólico (Tablas 2 y 3), signos clínicos junto a los hallazgos de la necropsia y la no respuesta al tratamiento con azul de metileno se recomendó el suministro de $150 \mathrm{~g} /$ día por vaca de una mezcla mineral con $18 \%$ de fósforo, mientras se incluía en la dieta los subproductos de la remolacha y colza. Posteriormente no se observó presentación de nuevos casos en los rebaños.
Las concentraciones plasmáticas de fósforo obtenidas en las tres lecherías afectadas fueron inferiores al valor mínimo de referencia para animales en condiciones similares a los afectados y a los de lecherías de la misma zona en donde no fueron encontrados animales afectados (Tabla 2). También se observó una anemia, identificada por la hipohemoglobinemia en los animales (Tabla 3). En rebaños afectados por carencia de fósforo, ubicados en zonas deficientes en este elemento, los terneros y las vacas no lactantes presentan con frecuencia normofosfatemia; las vacas a la mitad y final de la lactancia una normo o leve hipofosfatemia y las vacas con menos de 2 meses de lactancia una hipofosfatemia (Tabla 3).

\section{DISCUSIÓN}

Las vacas en lactancia de los rebaños afectados presentaron una fosfatemia de $0.65-0.97 \mathrm{mmol} / \mathrm{L}$ y los animales enfermos cifras de 0.13 a $0.48 \mathrm{mmol} / \mathrm{L}$, además de anemia (1). A su vez se encontraron vacas con concentraciones plasmáticas de fósforo inferiores a los $0.30 \mathrm{mmol} / \mathrm{L}$ sin signos clínicos (19).

Algunos animales afectados presentaron bajas concentraciones de cobre en hígado y sangre $(7,20)$, a su vez, limitaciones de carácter técnico no permitieron evaluar

Tabla 3. Concentraciones medias, desviación estándar (DE), rango, valor $\mathrm{H}$ e intervalo de referencia de los metabolitos sanguíneos de 21 vacas lecheras de rebaños que presentaron vacas con hemoglobinuria en el periodo pos-parto.

\begin{tabular}{lcccccc}
\hline & Unidad & Media & DE & Rango & H* & $\begin{array}{c}\text { Intervalo } \\
\text { Referencia** }\end{array}$ \\
\hline Hemoglobina & $\mathrm{g} / \mathrm{L}$ & 88 & 9.0 & $74-100$ & -3.3 & $98-130$ \\
Glucosa & $\mathrm{mmol} / \mathrm{L}$ & 3.14 & 0.33 & $2.75-3.60$ & -0.2 & $2.3-4.3$ \\
Urea & $\mathrm{mmol} / \mathrm{L}$ & 3.04 & 0.65 & $2.39-3.89$ & -1.3 & $2.2-7.0$ \\
Proteína & $\mathrm{g} / \mathrm{L}$ & 73.0 & 5.0 & $66-79$ & -0.1 & $66-90$ \\
Albúmina & $\mathrm{g} / \mathrm{L}$ & 31.9 & 3.3 & $28-38$ & -0.1 & $26-38$ \\
Globulina & $\mathrm{g} / \mathrm{L}$ & 41.3 & 6.3 & $34-51$ & 0.2 & $28-52$ \\
Calcio & $\mathrm{mmol} / \mathrm{L}$ & 2.49 & 0.17 & $2.33-2.66$ & 1.3 & $2.00-2.60$ \\
Fósforo & $\mathrm{mmol} / \mathrm{L}$ & 0.57 & 0.18 & $0.39-0.78$ & -3.8 & $1.10-2.30$ \\
Magnesio & $\mathrm{mmol} / \mathrm{L}$ & 1.03 & 0.11 & $0.87-1.14$ & 1.1 & $0.66-1.14$ \\
Sodio & $\mathrm{mmol} / \mathrm{L}$ & 145 & 3 & $141-150$ & 0.2 & $134-154$ \\
Potasio & $\mathrm{mmol} / \mathrm{L}$ & 4.88 & 0.16 & $4.67-5.15$ & -0.2 & $3.92-6.08$ \\
\hline
\end{tabular}

*H:(media del grupo - media de referencia)/desviación estándar referencia. ** Límites de referencia establecidos en el Laboratorio de Patología Clínica Veterinaria, Universidad austral de Chile(18). 
las concentraciones de cobre en hígado y sangre tanto de los animales muertos como de otros de los rebaños afectados. Por otro lado, las concentraciones de colesterol y proteínas plasmáticas fueron similares a animales no afectados (20).

Se describe que el uso de dietas con derivados de la remolacha predisponen a la hipofosfatemia, ya que poseen un bajo contenido de fósforo $(<0.01 \%)$ y elevado de Ca $(>1.0 \%)(1,21)$. A su vez, la ración de los 3 rebaños incluía coseta y/o hoja de remolacha (Tabla 1), ingredientes asociados a la cercanía de una industria azucarera en pleno período de producción. Además, la dieta incluía afrecho de colza, alimento que se asocia a la enfermedad por su aporte de oxidantes S-metilcisteína que producen hemólisis intravascular (10).
Basado en la historia, signos clínicos, hallazgos de necropsia, exámenes de laboratorio, falta de respuesta clínica al tratamiento por intoxicación por nitritos y sumado a la ausencia de nuevos casos posterior al tratamiento con el suplemento con fósforo, se diagnosticó clínicamente la enfermedad hemoglobinuria posparto, ocasionada por una hipofosfatemia de origen nutricional (16).

Finalmente, se concluye que en sur de Chile la presentación de la hemoglobinuria posparto se asoció a la hipofosfatemia inducida por el consumo de plantas crucíferas o subproductos de ellas, si bien la presentación de la enfermedad podría estar relacionada a las carencias de selenio y cobre o de dietas oxidantes que también predisponen a la enfermedad.

\section{REFERENCIAS}

1. Macwilliams PS, Searcy GP, Bellamy JE. Bovine postparturient hemoglobinuria: a review of the literature. Can Vet J 1982; 23:309-12.

2. Martinovich D, Woodhouse DA. Postparturient haemoglobinuria in cattle: a Heinz body haemolytic anaemia. N Z Vet J 1971; 19:259-63.

3. Ogawa E, Kobayashi K, Yoshiura $\mathrm{N}$, Mukai J. Bovine postparturient hemoglobinemia: hypophosphatemia and metabolic disorder in red blood cells. Am J Vet Res 1987; 48:1300-3.

4. Jubb TF, Jerrett IV, Browning JW, Thomas KW. Haemoglobinuria and hypophosphataemia in postparturient dairy cows without dietary deficiency of phosphorus. Aust Vet J 1990; 67:86-9.

5. Ellison RS, Young BJ, Read DH. Bovine postparturient haemoglobinuria: two distinct entities in New Zealand. N Z Vet J $1986 ; 34: 7-10$.
6. Dhillon KS, Singh J, Ashuma, Kumar H, Bal MS, Sandhu KS et al. Haemoglobinuria in dairy herds. Vet Rec 2007; 160:276.

7. Smith B. The effects of copper supplementation on stock health and production. I. Field investigations into the effects of copper supplementation on stock health in dairy herds with a history of postparturient haemoglobinuria. N Z Vet J 1975; 23:73-7.

8. Wang $\mathrm{XL}$, Gallagher $\mathrm{CH}$, McClure TJ, Reeve VE, Canfield PJ. Bovine postparturient haemoglobinuria: effect of inorganic phosphate on red cell metabolism. Res Vet Sci 1985; 39:333-9.

9. Feldman BF, Zinkl JG, Jain NC. Schalm's Veterinary Hematology. 5 ed. Baltimore: Lippincott Williams \& Wilkins; 2000. 
10. Yates D. Disorders of phosphorus metabolism. Large Animal Internal Medicine. USA: Smith B Mosby Company; 1990.

11. Smith B. Copper and molybdenum imbalance in relationship to postparturient haemoglobinuria in cattle. N Z Vet J 1973; 21:240.

12. Underwood EJ, Suttle N. The mineral nutrition of livestock. 3 ed. Edinburgh, UK: Penicuik; 1999.

13. Araya O, Wittwer F, González S. Estudio hematológico en vacas de lechería suplementadas con col forrajera (Brassica oleracea). Arch Med Vet $1971 ; 3: 80-83$.

14. Kaneko JJ, Harvey JW, Bruss ML. Clinical Biochemistry of Domestic Animals. Sixth ed. San Diego: Academic Press; 2008.

15. Thompson JC, Badger SB. Outbreak of postparturient haemoglobinuria in an autumn calving dairy herd. N Z Vet J 1999; 47:180-3.

16. Radostits OM, Gay CC, Blood DC, Hinchcliff KW. Enfermedades metabólicas. Medicina Veterinaria. Tratado de las enfermedades del ganado bovino, ovino, porcino, caprino y equino, Radostits OM, Gay CC, Blood DC, Hinchcliff KW. Madrid, España: McGraw-Hill Interamericana. 2002.
17. Carlson GP, Aleman M. Heinz body hemolytic anemia. Large Animal Internal Medicine, USA: Smith $B$. Mosby Company; 2008.

18. Wittwer $F$, Bohmwald $H$, Contreras PA, Filosa J. Análisis de los resultados de perfiles metabólicos obtenidos en rebaños lecheros en Chile. Arch Med Vet 1987; 19:35-45.

19. Stockdale CR, Moyes TE, Dyson R. Acute postparturient haemoglobinuria in dairy cows and phosphorus status. Aust Vet J 2005; 83:362-6.

20. Gardner DE, Martinovich D, Woodhouse DA. Haematological and biochemical findings in bovine postparturient haemoglobinuria and the accompanying Heinz-body anaemia. N Z Vet J 1976; 24:117-22.

21. Anrique $\mathrm{R}$, Fuschslocher $\mathrm{R}$, Iraira $\mathrm{S}$, Saldaña R. Composición de alimentos para el ganado bovino. 4 ed. Valdivia, Chile: Imprenta America; 2010. 